\title{
Доработка семян перца сладкого на пневмосортировальном столе
}

\author{
Refinement of sweet pepper seeds on a pneumatic sorting table
}

Янченко А.В., Меньших А.М., Азопков М.И., Голубович В.С.

\section{Аннотация}

С развитием технологий производства и внедрением автоматизированных технологических процессов возникают повышенные требования к качеству посевного материала. Посевные качества семян, отвечающие требованиям ГОСТ 32592-2013 «Семена овощных, бахчевых культур, кормовых корнеплодов и кормовой капусты. Сортовые и посевные качества. Общие технические условия», не всегда удовлетворяют требованиям, предъявляемым к семенам и их качеству. Для автоматизации посева семена должны быть выровнены по размеру, иметь высокие показатели энергии и лабораторной всхожести. Один из способов повышения посевных качеств семян перца сладкого - доработка семян на пневмосортировальном столе с сепарацией семян по их удельной плотности, выполненности. Работа проводилась на экспериментальной базе ВНИИО - филиала ФГБНУ ФНЦО и цеха доработки семян Агрохолдинга «Поиск». В опытах изучались возможности подготовки семян с использованием пневмосортировального стола ПСС-1, изготовленного на Воронежском ОАО ГСКБ «Зерномаш». Исследования проводили на семенах перца сладкого. При обработке выделяются и направляются в приемники пять фракций семян, условно легкие примеси, промежуточная фракция, две основных фракции очищенного материала и тяжелые примеси, в т.ч. минеральные частицы (камешки, песчинки, которые имеют одинаковый размер с семенами, но значительно их тяжелее). Для более качественного разделения фракций в приемниках предусмотрены разделительные заслонки, которые можно смещать относительно поступаемых семян с деки. В конструкции машины предусмотрена возможность изменения: угла продольного наклона деки от 0 до 8 град., угла поперечного наклона деки от 0 до 9 градусов, частоты колебаний деки от 300 до 500 кол/мин., и амплитуды - позиционно - 3 и 5 мм. Доработка семенного вороха на пневмосортировальном столе ПСС1 дает возможность выделить семена с более высокими посевными качествами, пригодные для современных интенсивных точных технологий в овощеводстве. Основное направление реализации высококачественного семенного материала - товарные производители. Несмотря на то, что стоимость высококачественных семян на порядок выше, положительно на экономический эффект влияет отказ от пикировки, высев семян перца напрямую в кассеты, и более качественная рассада, так как за счет энергии прорастания рассада растет более равномерно и дружно.

Ключевые слова: фракции семян, семенной ворох, посевные качества семян, перец сладкий, пневмосортировальный стол, сепарация по плотности.

Для цитирования: Доработка семян перца сладкого на пневмосортировальном столе / А.В. Янченко, А.М. Меньших , М.И. Азопков, В.С. Голубович // Картофель и овощи. 2020. №3. С. 28-30. https://doi.org/10.25630/PAV.2020.16.90.004
Yanchenko A.V., Menshikh A.M. , Azopkov M.I., Golubovich V.S.

\section{Abstract}

With the development of production technologies and the introduction of automated technological processes, there are increased requirements for the quality of seed. Sowing quality of seeds that meet the requirements of GOST 32592-2013 «Seeds of vegetables, melons, fodder root crops and fodder cabbage. Varietal and sowing qualities. General technical conditions» do not always satisfy the requirements for seeds and their quality. To automate sowing, seeds must be aligned in size and have high energy and laboratory germination rates. One of the ways to improve the sowing qualities of seeds of sweet pepper is to refine the seeds on a pneumatic sorting table with separation of seeds according to their specific gravity, performance. The work was carried out on the experimental basis of ARRIVG - branch Federal State Budget Scientific Institution Federal Scientific Center and the seed finishing shop of the Poisk agroholding. In the experiments, we studied the possibilities of preparing seeds using the PSS-1 pneumatic sorting table manufactured at the Voronezh GSKB Zernomash. During processing, five fractions of seeds, conditionally light impurities, an intermediate fraction, two main fractions of the purified material and heavy impurities are isolated and sent to the receivers, including mineral particles (pebbles, grains of sand, which are the same size with seeds, but they are much heavier). For a better separation of fractions, separators are provided in the receivers, which can be shifted relative to the incoming seeds from the deck. The design of the machine provides for the possibility of changing: the angle of the longitudinal inclination of the deck from 0 to 8 degrees., The angle of the transverse inclination of the deck from 0 to 9 degrees, the oscillation frequency of the deck from 300 to 500 counts $/ \mathrm{min}$., and the amplitude - positionally -3 and $5 \mathrm{~mm}$. Completion of the seed pile on the PSS-1 pneumatic sorting table makes it possible to select seeds with higher sowing qualities that are suitable for modern intensive precision technologies in vegetable growing. The main direction of the sale of high-quality seed material is commodity producers. Despite the fact that the cost of high-quality seeds is an order of magnitude higher, the positive effect on the economic effect is the refusal to pick, sowing pepper seeds directly into cassettes, and better seedlings, since seedling grows more uniformly and amicably due to the germination energy.

Key words: seed fractions, seed heap, seeding quality of seeds, sweet pepper, pneumosorting table, density separation.

For citing: Refinement of sweet pepper seeds on a pneumatic sorting table / A.V. Yanchenko, A.M. Menshikh, M.I. Azopkov, V.S. Golubovich / Potato and vegetables. 2020. №3. Pp. 28-30. https://doi. org/10.25630/PAV.2020.16.90.004 (In Russ.)
$\mathrm{B}$ недрение современных технологий производства высококачественной овощной продукции в значительной мере обусловлено возможностями обеспечения семенами высокого качества как по сортовым, так и посевным и технологическим качествам. Кроме высо- кой сортовой чистоты и предрасположенности к формированию выровненной, однородной продукции, семена должны иметь высокую всхожесть и дружность прорастания.

Наиболее распространенный способ повышения посевных качеств семян - их калибровка, при которой от- сеиваются выровненные по размеру семена. Однако калибровка не всегда дает положительный эффект. Основная причина в том, что зачастую пустотелые, щуплые семена, имеют одинаковый размер и хорошо сформированы. Однако, имея одинаковый размер, семена могут значительно от- 
личаться друг от друга по плотности [1]. Такие семена можно частично отделить из общей массы при помощи ветро-решетных машин, корректная настройка вентилятора позволяет удалить легкие пустотелые семена.

Для удаления из вороха семян трудноотделимых примесей и семян, отличающихся друг от друга по выполненности, используют пневмосортировальный стол, который разделяет ворох семян на фракции исходя из их удельной плотности, что позволяет получать выровненные по плотности семена. В результате с основного вороха семян можно выделить часть семян, посевные показатели которых будут значительно выше исходных [2, 3].

Существует большое разнообразие пневмосортировальных столов, которые условно можно разделить на два вида по направлению вибрации относительно потока семян: продольные и поперечные. Учитывая большое разнообразие форм и размеров семян овощных культур наибольший интерес в очистке и доработке семян представляют пневмосортировальные столы с тканевой декой и поперечной вибрацией.

НабазеОООГСКБ «Зерноочистка» был разработан пневмофрикционный сортировальный стол ПСС-1, предназначенный для очистки ceмян овощных и пряноароматических культур от трудноотделимых примесей, отличающихся от основной культуры по плотности, форме и свойствам поверхности. Машина очистки и доработки семенного вороха может работать с любыми по размеру и плотности семенами овощных культур. Основные узлы машины: станина, дека сменная, виброрама, привод, вентилятор, механизмы для регулировки углов наклона деки, подвески, регулятор интенсивности подачи воздуха и бункер-питатель.

В процессе работы машины обрабатываемый материал через загрузочный бункер-питатель подается на тканевую поверхность деки, продуваемую потоками воздуха и совершающую колебательное движение под углом к горизонтальной поверхности. Наклон поверхности деки регулируется двумя регулировочными винтами. Продольный угол относительно потока семян влияет на время нахождения семян на деке. Поперечный угол влияет на распределение потока семян по деке и разделение вороха семян на различные по плотности фракции. При этом обрабатываемый материал приходит в псевдо-сжиженное состояние и за
Таблица 1. Ведомость определения производительности образца пневмосортировального стола ПСС-1 на семенах перца сладкого, сорт Белозерка, 2019 год

\begin{tabular}{|c|c|c|c|c|c|c|c|}
\hline \multirow{2}{*}{ Повторность } & \multicolumn{5}{|c|}{ Масса проб за 30 с по выходам, г } & \multirow{2}{*}{$\begin{array}{c}\text { Масса } \\
\text { всего } \\
\text { семян, г }\end{array}$} & \multirow{2}{*}{$\begin{array}{c}\text { Произво- } \\
\text { дительность, } \\
\text { кг/ч }\end{array}$} \\
\hline & 1 & 2 & 3 & 4 & 5 & & \\
\hline 1 & 83 & 179 & 351 & 498 & 95 & 1207 & 144,84 \\
\hline 2 & 93 & 182 & 360 & 463 & 124 & 1224 & 146,88 \\
\hline 3 & 123 & 183 & 341 & 557 & 54 & 1261 & 151,32 \\
\hline 4 & 82 & 161 & 326 & 513 & 129 & 1215 & 145,80 \\
\hline 5 & 117 & 209 & 356 & 479 & 58 & 1224 & 146,88 \\
\hline 6 & 138 & 205 & 384 & 479 & 66 & 1278 & 153,36 \\
\hline 7 & 83 & 185 & 396 & 523 & 55 & 1249 & 149,88 \\
\hline 8 & 83 & 188 & 404 & 495 & 55 & 1233 & 147,96 \\
\hline 9 & 93 & 218 & 427 & 505 & 53 & 1305 & 156,60 \\
\hline 10 & 67 & 175 & 348 & 661 & 66 & 1327 & 159,24 \\
\hline Среднее значение & 96,2 & 188,5 & 369,3 & 517,3 & 75,5 & 1252,3 & 150,28 \\
\hline $\begin{array}{l}\text { Среднеквадратич- } \\
\text { ное отклонение }\end{array}$ & 21,20 & 16,36 & 30,32 & 54,02 & 28,09 & 38,11 & 4,57 \\
\hline Выходпо фракциям,\% & 7,68 & 15,05 & 29,49 & 41,31 & 6,03 & 100,00 & \\
\hline
\end{tabular}

счет направленных воздействий поверхности деки (колебаний) и подачи воздуха разделяется на однородные потоки, в т.ч. поток примесей.

При обработке выделяются и направляются в приемники пять фракций семян: условно легкие примеси, промежуточная фракция, две основные фракции очищенного материала и тяжелые примеси, в т.ч. минеральные частицы (камешки, песчинки, которые имеют одинаковый размер с семенами, но значительно их тяжелее). Для более качественного разделения фракций в приемниках предусмотрены разделительные заслонки, которые можно смещать относительно поступаемых семян с деки.

В конструкции машины предусмотрена возможность изменения следующих параметров: угла продольного наклона деки от 0 до 8 градусов, угла поперечного наклона деки от 0 до 9 градусов, частоты колебаний деки от 300 до 500 кол/мин., и амплитуды - позиционно - 3 и 5 мм.

Цель исследований: оценить эффективность доработки семян перца

сладкого на пневмосортировальном столе ПСС-1.

Условия, материалы и методы исследований

Работа проводилась на экспериментальной базе ВНИИО - филиала ФГБНУ ФНЦО и цеха доработки семян Агрохолдинга «Поиск». В опытах изучались возможности подготовки семян с использованием пневмосортировального стола ПСС-1, изготовленным на Воронежском ОАО ГСКБ «Зерномаш». Исследования проводили на семенах перца сладкого.

Обработка семян проводилась в два этапа:

- ворох семян очищался от крупного и мелкого мусора на ветро-решетной машине СМ-0,15, в результате получены выровненные по размеру семена пригодные для точного высева;

- после очистки семена подвергались сортировке по удельной плотности на ПСС-1.

\section{Результаты исследований}

Доработка семенного вороха перца сладкого на ПСС-1 показала, что машина функционально в целом удовлетво-

Таблица 2. Посевные показатели качества семян перца сладкого, сорт Белозерка, 2019 год

\begin{tabular}{|c|c|c|c|}
\hline \multirow{2}{*}{ Фракция } & \multicolumn{3}{|c|}{ Показатели } \\
\cline { 2 - 4 } & Чистота, \% & Энергия прорастания, \% & Лабораторная всхожесть, \% \\
\hline Исходная & 96,2 & 52 & 84 \\
\hline I & 75,3 & 35 & 68 \\
\hline II & 95,4 & 56 & 80 \\
\hline III & 99,1 & 78 & 90 \\
\hline IV & 99,3 & 79 & 92 \\
\hline V & 95,8 & 65 & 83 \\
\hline
\end{tabular}




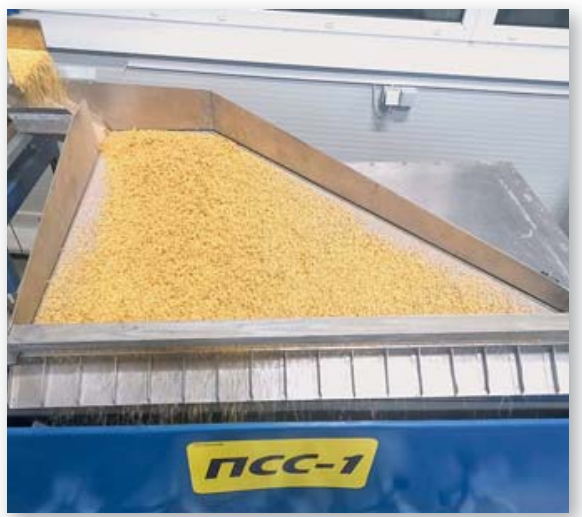

Доработка семян перца сладкого на ПСС-1

ряет поставленным требованиям: происходит удаление невыполненных, легких, дробленых семян из вороха семян после первичной очистки, а также выделение фракции семян с более высокими посевными показателями.

При этом производительность машины в процессе сортировки семян, прошедших первичную очистку, колебалась в диапазоне 144,84159,24 кг/ч семян перца сладкого. Средняя производительность ПСС-1 составила 150,28 кг/ч (табл. 1).

B процессе доработки семян на ПСС-1 перца сладкого сорта Белозерка использовали следующие регулировки: поперечный наклон деки 5 градусов; продольный наклон деки 8,6 градусов; амплитуда колебаний деки 5 мм; частота колебаний 405415 кол/мин. Заслонка приоткрыта на $60-70 \%$ для создания сжиженного потока вороха семян. Вибропитатель отрегулирован на бесперебойную равномерную подачу семян на деку со скоростью 2,4-2,6 кг/мин. Следует отметить, что настройки выбираются визуально по потоку семян и могут изменяться при доработке семян другого сорта или партии.

После доработки вороха семян, пропущенных через ПСС-1, получили пять фракций семян различных по плотности, чистоте и всхожести у каждой партии (табл. 2).

В результате доработки семян удалось выделить фракцию семян со всхожестью выше показателя в исходной партии на 7-8\%. У выделенной по плотности фракции семян была отмечена повышенная энергия прорастания на 19-26\% по отношению к исходной партии. Энергия прорастания - основной показатель, влияющий на дружность появления всходов. Повреждений семян перца сладкого в процессе доработки на ПСС-1 не наблюдалось
При объединении III и IV фракций получили около $70 \%$ по весу от исходной партии семян с более высокими посевными показателями. Оставшиеся семена не годятся для высокоточных технологических процессов. Поэтому себестоимость производства семян, отсеянных в процессе доработки, ложится на оставшиеся высококачественные семена. В результате стоимость доработанных семян становится выше на 40-45\%. Такие семена предлагаются в основном для специализированного профессионального рынка и стоимость их на порядок выше семенного вороха. При реализации семян II и V фракций стоимость высококачественных семян может быть выше исходной стоимости на 15-25\% [4].

Посев семян перца сладкого с пикировкой начинается за 50-60 дней до высадки рассады. Использование высококачественных семян, дает возможность высевать автоматизировано семена в кассеты без пикировки. При

\section{Библиографический список}

1.Быковский Ю.А. и др. Предпосылки получения выровненных всходов овощных культур // Картофель и овощи. 2017. №8. C. $18-21$.

2.Шайманов А.А., Янченко А.В. Предлагаем комплекс машин для предпосевной подготовки семян // Картофель и овощи. 2008. №2. С. 23

З.Тарасенко А.П., Оробинский В.И., Мироненко Д.Н. Качество очистки семян на пневмосортировальных столах // Механизация и электрификация сельского хозяйства. 2009. №3. С. 10-11.

4.Нужаева Е.А. Особенности ассортимента и оценка качества реализуемых населению семян сортов томата и перца // Вестник молодых ученых и специалистов Самарского университета. 2018. №2 (13). C. 41-47.

5.Пышная О.Н., Мамедов М.И., Джос Е.А. Выращивание перца сладкого в теплицах и открытом грунте // Овощи России. 2010. № 2 (8). С. 44-49.

\section{Об авторах}

Янченко Алексей Владимирович, канд. с.-х. наук, в.н.с. отдела технологий и инноваций

Меньших Александр Михайлович, канд. с.-х. наук, в.н.с. отдела технологий и инноваций

Азопков Максим Игоревич, канд. с.-х. наук, в.н.с. отдела технологий и инноваций

Голубович Виктор Сергеевич, канд. с.-х. наук, с.н.с. отдела технологий и инноваций

ВНИИО - филиал ФГБНУ ФНЦО E-mail:vniioh@yandex.ru этом высев рекомендуют сместить на 45-50 дней до высадки рассады [5].

Повышение всхожести семян при их автоматическом посеве в кассеты для выращивания рассады без пикировки способствует снижению затрат на 7-8\%, так как при более высокой всхожести отпадает необходимость в дополнительных кассетах и обеспечивается расчетное количество рассады. Повышение энергии прорастания также способствует дружному росту и развитию рассады.

\section{Выводы}

Таким образом, при использовании в производстве интенсивных технологий точного высева семян, возникает потребность в высококачественных семенах. Доработка семенного вороха на пневмосортировальном столе ПСС-1 дает возможность выделить семена с более высокими посевными качествами, пригодные для современных интенсивных точных технологий в овощеводстве.

\section{References}

1.Bykovsky Yu.A. et al. Prerequisites for obtaining aligned shoots of vegetable crops. Potato and vegetables. 2017. No. 8. Pp. 18-21 (In Russ.).

2.Shaimanov A.A., Yanchenko A.V. We offer a set of machines for seedbed preparation. Potato and vegetables. 2008. No. 2. Pp. 23 (In Russ.).

3.Tarasenko A.P., Orobinsky V.I. Mironenko D.N. The quality of seed cleaning on pneumatic sorting tables. Mechanization and electrification of agriculture. 2009. No. 3. Pp. 10-11 (In Russ.).

4.Nuzaeva E.A. Peculiarities of the assortment and quality assessment of seeds of tomato and pepper varieties sold to the population. Bulletin of young scientists and specialists of Samara University. 2018. No 2 (13). Pp. 41-47 (In Russ.).

5.Pyshnaya O.N., Mamedov M.I., Jos E.A. Growing sweet pepper in greenhouses and open ground. Vegetables of Russia. 2010. No. 2 (8). Pp. 44-49 (In Russ.).

\section{Author details}

Yanchenko A.V., Cand. Sci. (Agr.), leading research fellow of Laboratory for mechanization of seed production of the Technology and Innovation Department

Menshikh A.M., Cand. Sci. (Agr.), leading research fellow of Department of Technology and Innovation

Azopkov M.I., Cand. Sci. (Agr.), leading research fellow of Department of Technology and Innovation

Golubovich V.S., Cand. Sci. (Agr.), senior research fellow of Department of Technology and Innovation

ARRIVG - branch of FSBSI FSVC E-mail:vniioh@yandex.ru 